\title{
An empirical study on evaluating training program: A case study of university employee
}

\author{
Hamid Reza Rezazadeh Bahadoran ${ }^{\mathrm{a}}$, Aliakbar Khosravi Babadadi ${ }^{\mathrm{a}}$ and Sara Tountab Haghighi ${ }^{\mathrm{a}^{*}}$
}

${ }^{a}$ Department of Psychology and Social Science, Islamic Azad University, Central Branch, Tehran, Iran

\begin{tabular}{l}
\hline A R T I C L E I N F O \\
\hline Article history: \\
Received February 1, 2011 \\
Received in Revised form \\
April, 10, 2011 \\
Accepted 12 April 2011 \\
Available online \\
14 April 2011 \\
\hline Keywords: \\
Training program \\
Efficiency \\
Learning studies \\
Kirkpatrick model
\end{tabular}
\begin{abstract}
A B S T R A C T
In this paper, we present an empirical study on measuring the effects of training programs on efficiency of university employee. The proposed model of this paper uses Kirkpatrick four level models based on some questionnaire. The questions are divided into four different groups of reflection, leaning, behavior and efficiency and the feedback are collected using Likert scales. We perform some statistical tests to analyze the results and conclude that staff training has relatively positive impact on all four items. In addition, the effects of different personal characteristics such as age, gender and marriage conditions are investigated on all four levels of Kirkpatrick's model. The results indicate that the Kirkpatrick could be implemented for measuring the effects of training programs, efficiently.
\end{abstract}

\section{Introduction}

Knowledge plays an important role on staff efficiency and there are literally different methods to increase the level of education on various organizations such as providing short courses, books, educational movies, etc. One of the most important issues is to understand how effective is training programs. There are different studies for measuring the effects of training based on different studies. Ducharme and Feldman ( 1992) compared different staff training strategies to promote generalized teaching skills. McDonnell (1997) studied the effects of training care staff to manage challenging behavior for three-day course studies. Rice et al. (1985) studied crisis prevention and intervention training for psychiatric hospital staff. Richman et al. (1988) investigated the effects of self-monitoring and supervisor feedback on staff performance for a residential setting. McDonnell et al. (2008) studied the effects of a 3-day training program in the management of aggressive behavior in services for staff with autism spectrum disorders were investigated using a quasi-experimental design. An experimental people received training for a 10-month period and a contrast group, which had received no training. The study indicated that staff training increased career confidence, but there were no training effects of measures of staff coping, support or perceived control of challenging behaviors. The study also indicated that staff training could increase staff confidence in managing aggression in

* Corresponding author. Tel. +989121082897

E-mail addresses: sara_th52@yahoo.com (S. Tountab Haghighi) 
people with autism spectrum disorders. Arthur (1994) presented a comprehensive survey on different customer-service training for academic libraries. Galloway and Ho (1996) presented a model of service quality for measuring the efficiency of service training. Daly et al. (2008) examined the effect of improvisation training, as used in schools of acting, in preparing front-stage service employees performed their roles when interacting with customers as cabin crew in a regional Irish airlines. Kirkpatrick (1994) presented a well-known method for evaluating training effectiveness of organizations. In his model, there are four levels of reaction, learning, behavior and results and the performance of learning is measured based on these levels.

In this paper, we study the impact of service training for university employees in one of private universities in Iran. The model uses Likert scale from one to five for a questionnaire consists of thirty questions and the results are analyzed using parametric statistical tests. The organization of this paper first presents the proposed model and next it explains the details of the implementation of the proposed model for the case study in section 2 and 3, respectively. Finally, concluding remarks are presented in the last section to summarize the contribution of the paper.

\section{Methodology}

Learning plays a vital role for the success of any organization and there is no doubt that any organization needs to have employees with high level of skills and knowledge to survive in a competitive market. Service training is one of the well-known methods for increasing the level of people's knowledge. Service training has different advantages such as promoting employees' levels, adjusting staffs' behavior and increasing their disciplines, which lead organizations to maintain operations, which are more efficient. There are many evidences, which indicate that service training has positive impact on the efficiency of organization such as reducing the number of incidents, preventing waste of resources, etc.

\subsection{Service learning objectives}

There are different learning objectives associated with any service learning programs. In summary, we could categorize the objectives into three different groups of organizational, employee and social issues as follows.

\subsubsection{Organizational objectives}

In order to meet organizational needs we need to maintain qualified employees who have minimum requirement skills. In addition, the organizational objectives require cooperative spirit among employees, group team-work followed by working regulations.

\subsubsection{Employees objective}

There must be a good relationship between employee's personality and their responsibilities. In other word, when an employee performs his duties better, he/she tends to have a better feeling and more confidence.

\subsubsection{Social objective}

There is also an important aspect of organizational objectives, which is the contribution to social system. In fact, we need to emphasis that social objectives play important role on organizational needs. 


\subsection{Kirkpatrick model}

Kirkpatrick model is one of the most important techniques for measuring the impact of training programs. The method consists of four major levels of reaction, behavior, learning and results. In the reaction level, the model studies how the learners react to the learning process while the learning focuses on the impact of the learning on increasing the knowledge and skills. The behavior is associated with the capability to execute the learned skills practically while the results are on the items such as efficiency, monetary, moral, etc. The first two levels are also called hot evaluations while the next two levels are called cold evaluations. The reason is that we could almost instantly measure the impact of the first two levels while the impact of the second two levels is measured with delay.

\section{The case study}

In this paper, we implement the proposed model of this paper to study the impact of learning programs held for some university staff. The total number of people who were working for the university was 667. In order to find out the number of sample size we have used the following statistical sampling technique,

$n=\frac{N \times z_{\alpha / 2}^{2} \times p \times q}{\varepsilon^{2} \times(N-1)+z_{\alpha / 2}^{2} \times p \times q}$,

where $N$ is the population size, $p=1-q$ represents the yes/no categories, $z_{\alpha / 2}$ is CDF of normal distribution and finally $\varepsilon$ is the error term. Since we have $p=0.5, z_{\alpha / 2}=1.96$ and $N=667$, the number of sample size is calculated as $n=247$. Table 1 shows the frequencies of the people who participated in our survey.

\section{Table 1}

Frequency of the different people who participated in the survey

\begin{tabular}{lccccccc}
\hline Department & Frequency & Percentage & Age & Frequency & Percentage & Sex & Frequency \\
\hline Administration & 133 & 8.53 & $30-20$ & 31 & 12.7 & Women & 178 \\
Education & 17 & 9.6 & $30-40$ & 169 & 69 & Men & 67 \\
Social Science & 14 & 8.5 & $40-50$ & 43 & 17.6 & No response & 2 \\
Engineering & 51 & 20.6 & $>50$ & 2 & 0.8 & & \\
Industrial Engineering & 8 & 2.3 & No response & 2 & - & & \\
Management and Accounting & 24 & 7.9 & & & & \\
Total & 247 & 100 & & 247 & 100 & \\
\hline
\end{tabular}

As we can observe from Table 1, over half of the people who participated in our survey are from administration department. These are the people who are responsible for registering the students, performing financial transaction, etc and their responsibilities are important to increase customer's satisfaction. According to Table 1, most people who participated in our survey are between 30 to 50 years old and over two third of the particpants are women. In addition, 32\% of the people who took part in our survey had less than 10 years of job experience, $46.5 \%$ between 11 to 16 years of job experience, $16.2 \%$ between 16 to 20 years of job experience and 3.3\% had more than 20 years of job experience. $23.4 \%$ of the people who participated in our survey had only 12 years of educational background, $15.6 \%$ with 14 years of educational background, $49.6 \%$ with batchlour degree and $11.5 \%$ hold master degrees.

\subsection{The results}

In order to analyze the results of the data gathered from this survey we have performed a normality test to examine whether we could use parameteric statistics for the data and found out that the skewness of our data was less than 1 . Therefore, we have used regular $t$-student test to analyze the data. The questionnarie of our survey consists of 30 questions. Table 2 summarizes the results of our survey for measuring the impact of training programs on people's reflection. 
Table 2

The impact of training programs on people's reflection

\begin{tabular}{llccc}
\hline$\#$ & Question & Mean & t-student & P-value \\
\hline 1 & Instructor background knowledge & 2.92 & 20.97 & 0.001 \\
2 & How interesting is the teaching & 2.77 & 15.50 & 0.001 \\
3 & Instructor expertise on training program & 2.86 & 16.84 & 0.001 \\
4 & Instructor's equipments for training program & 2.56 & 9.81 & 0.001 \\
5 & Instructor's attempt to use useful software packages & 2.50 & 8.42 & 0.001 \\
6 & Instructor's ability to use high tech facilites & 2.39 & 6.57 & 0.001 \\
7 & Instructor's ability to use multimedia devices & 2.27 & 4.06 & 0.001 \\
8 & The quality of supporting equipments & 2.52 & 8.85 & 0.001 \\
9 & The relationship between the job and traing subject & 2.64 & 10.49 & 0.001 \\
10 & The relationship between the job and traing program & 2.64 & 10.18 & 0.001 \\
11 & How appropriate is the program for training program & 3.20 & 20.36 & 0.001 \\
\hline & Reflection & 2.66 & 17.20 & 0.001 \\
\hline
\end{tabular}

As we can observe all t-student values indicate the rejection the null hypothsis, having no impact, when the level of confidence is $1 \%$ and the degree of freedom is 246 . Therefore we can conclude the experimental mean is well above the theoretical mean for all 11 questions associated with reflection questions. In other words, the survey indicate that the training program reflected above average for these people. The impact of training programs on people's learning is demonstrated in Table 3 .

Table 3

The impact of training programs on people's learning

\begin{tabular}{clccc}
\hline$\#$ & Question & Mean & t-student & P-value \\
\hline 1 & Increasing participants' interest for learning & 2.90 & 16.42 & 0.001 \\
2 & The effects of the program on developing knowledge & 2.94 & 18.92 & 0.001 \\
3 & The effects of the program on learning & 2.83 & 15.35 & 0.001 \\
4 & The effects of the program on changing the style of learning & 2.56 & 9.81 & 0.001 \\
5 & The effects of the program on organizing different courses & 2.63 & 10.50 & 0.001 \\
6 & The effects of the program on getting actual results & 2.70 & 12.48 & 0.001 \\
7 & The effects of the program on increasing the overall knowledge & 2.27 & 4.06 & 0.001 \\
\hline & Learning & 2.78 & 16.73 & 0.001 \\
\hline
\end{tabular}

Again, we observe that the effects of experimental mean is well above the theoretical mean of 2, which means the training program could increase the participants' learning. Finally, table 4 summarizes the impact of questions on changing people's behavior.

\section{Table 4}

The impact of training programs to change on people's behavior

\begin{tabular}{llccc}
\hline$\#$ & Question & Mean & t-student & P-value \\
\hline 1 & The impact of training programs on increasing satisfaction & 2.60 & 9.61 & 0.001 \\
2 & The impact of training programs on changing behaviour & 2.52 & 9.57 & 0.001 \\
3 & The impact of training programs on reducing challenges & 2.28 & 4.12 & 0.001 \\
4 & The impact of training programs on receiving promotion & 2.52 & 8.04 & 0.001 \\
5 & The impact of training programs on expediting the due jobs & 2.73 & 12.03 & 0.001 \\
6 & The impact of training programs on reducing the works & 2.74 & 12.57 & 0.001 \\
7 & The impact of training programs on increasing the quality of jobs & 2.78 & 13.20 & 0.001 \\
8 & The impact of training programs on punctuality & 2.28 & 3.78 & 0.001 \\
9 & The impact of training programs on absorbing management support & 2.09 & 1.33 & 0.183 \\
10 & The impact of training programs on trouble shooting & 2.71 & 10.88 & 0.001 \\
11 & The impact of training programs on increasing creativity and innovations & 2.64 & 11.62 & 0.001 \\
12 & The impact of training programs on customer relationship management & 2.80 & 12.16 & 0.001 \\
\hline & The change on behaviour & 2.58 & 11.53 & 0.001 \\
\hline
\end{tabular}


Again, we have obtained the results, which mostly indicate that the mean of experimental results are mostly above the average, except one case, and we can conclude that the training programs could change staff's behavior. However, the results indicate that the training program did not have meaningful impact on receiving more support from management team. We have measured the impact of gender on our study and summarized the results on Table 5.

\section{Table 5}

The impact of gender on training program on behavior and efficiency

\begin{tabular}{|c|c|c|c|c|c|c|}
\hline Group & Gender & Mean & Std-dev. & t-student & d-freedom & $\mathrm{p}$-value \\
\hline \multirow{2}{*}{ Reflection } & Woman & 28.92 & 6.91 & \multirow[b]{2}{*}{1.35} & \multirow[b]{2}{*}{242} & \multirow{2}{*}{0.178} \\
\hline & Man & 30.20 & 5.87 & & & \\
\hline \multirow{2}{*}{ Learning } & Woman & 19.10 & 5.19 & \multirow[b]{2}{*}{1.75} & \multirow[b]{2}{*}{240} & \multirow[b]{2}{*}{0.080} \\
\hline & Man & 20.38 & 4.78 & & & \\
\hline \multirow{2}{*}{ Changing behavior } & Woman & 30.1 & 9.33 & \multirow{2}{*}{2.29} & \multirow{2}{*}{232} & \multirow{2}{*}{0.023} \\
\hline & Man & 33.12 & 8.14 & & & \\
\hline \multirow{2}{*}{ Efficiency } & Woman & 78.42 & 19.31 & \multirow{2}{*}{2.23} & \multirow{2}{*}{228} & \multirow{2}{*}{0.027} \\
\hline & Man & 83.90 & 15.64 & & & \\
\hline
\end{tabular}

Based on the results of Table 5 we can conclude that for $\alpha=.05$ there is a meaningful difference between two groups of men and women. In other words, male employees believe more than women do that training program has positive impact on increasing behavior and efficiency. We have repeated the same statistical test to study the effect of marriage on efficiency and behavior and the results are summarized in Table 6.

\section{Table 6}

The impact of marriage on training program on behavior and efficiency

\begin{tabular}{|c|c|c|c|c|c|c|}
\hline Group & Gender & Mean & Std-dev. & t-student & d-freedom & p-value \\
\hline \multirow{2}{*}{ Reflection } & Woman & 28.64 & 6.88 & \multirow{2}{*}{0.89} & \multirow[b]{2}{*}{242} & \multirow{2}{*}{0.373} \\
\hline & Man & 29.54 & 6.65 & & & \\
\hline \multirow{2}{*}{ Learning } & Woman & 18.24 & 6.47 & \multirow[b]{2}{*}{1.71} & \multirow[b]{2}{*}{240} & \multirow[b]{2}{*}{0.091} \\
\hline & Man & 19.82 & 4.58 & & & \\
\hline \multirow{2}{*}{ Changing behavior } & Woman & 30.58 & 9.65 & \multirow{2}{*}{0.36} & \multirow{2}{*}{232} & \multirow{2}{*}{0.715} \\
\hline & Man & 31.09 & 8.94 & & & \\
\hline \multirow{2}{*}{ Efficiency } & Woman & 77.64 & 20.75 & \multirow{2}{*}{1.11} & \multirow{2}{*}{228} & \multirow{2}{*}{0.268} \\
\hline & Man & 80.80 & 17.78 & & & \\
\hline
\end{tabular}

As we can observe from the results of Table 5, there is no meaningful difference between married and single people. Finally, it is interesting to study the effects of age on our survey which is summarized in Table 7.

\section{Table 7}

The impact of age on training program on behavior and efficiency

\begin{tabular}{|c|c|c|c|c|c|}
\hline Group & Gender & Mean & Std-dev. & t-student & p-value \\
\hline \multirow{3}{*}{ Reflection } & 20 to 30 & 33.29 & 6.05 & \multirow{3}{*}{6.42} & \multirow{3}{*}{0.002} \\
\hline & 31 to 40 & 28.81 & 6.99 & & \\
\hline & $>40$ & 28.59 & 5.09 & & \\
\hline \multirow{3}{*}{ Learning } & 20 to 30 & 21.80 & 5.22 & \multirow{3}{*}{3.79} & \multirow{3}{*}{0.024} \\
\hline & 31 to 40 & 19.23 & 5.28 & & \\
\hline & $>40$ & 18.84 & 4.10 & & \\
\hline \multirow{3}{*}{ Changing behavior } & 20 to 30 & 33.40 & 10.23 & \multirow{3}{*}{1.95} & \multirow{3}{*}{0.144} \\
\hline & 31 to 40 & 30.97 & 9.09 & & \\
\hline & $>40$ & 29.09 & 8.01 & & \\
\hline \multirow{3}{*}{ Efficiency } & 20 to 30 & 88.76 & 19.60 & \multirow{3}{*}{4.17} & \multirow{3}{*}{0.017} \\
\hline & 31 to 40 & 80.80 & 18.80 & & \\
\hline & $>40$ & 76.77 & 15.08 & & \\
\hline
\end{tabular}


It is clear from the results of Table 7 that there are meaningful differences between reflection, learning and efficiency for different ages.

\section{Conclusion}

In this paper, we have presented an empirical analysis to study the effects of learning programs on increasing employee's efficiency. The proposed model of this paper used Kirkpatrick four level models based on some questionnaire and analyzed the results. The survey was executed using Likert scale and the results were analyzed using parametric $t$-student tests. The results indicated that training programs has positive impact on reflection, learning and behavior. The results also indicated that there was no meaningful difference between married and single people but there was stronger belief among male people who took part in the survey that the training programs was useful. Finally, the results indicated that there were meaningful differences between reflection, learning and efficiency in different ages.

\section{Acknowledgment}

The authors would like to thank the anonymous referees for their constructive comments on the earlier version of this paper. Islamic Azad University financially supported the work and the authors would like to thank for the support.

\section{References}

Arthur, G. (1994). Customer-service training in academic libraries. The Journal of Academic Librarianship, 20(4), 219-222.

Daly, A., Grove, S. J., Dorsch, M. J., \& Fisk, R. P. (2009). The impact of improvisation training on service employees in a European airline: a case study type: Case study. European Journal of Marketing, 43(3-4), 459-471.

Ducharme, J. M., \& Feldman, M. A. ( 1992). Comparison of staff training strategies to promote generalized teaching skills. Journal of Applied Behavior Analysis, 25, 165-179.

Galloway, L., \& Ho, S. (1996). A model of service quality for training. Training for Quality, 4(1), 1926.

Kirkpatrick, D. L. (1994). Evaluating Training Programs: The Four Levels. San Francisco, CA: Berrett-Koehler

Likert, R. (1932). A Technique for the Measurement of Attitudes. Archives of Psychology, 140, 1-55.

McDonnell, A., Sturmey, P., Oliver, C. Cunningham, J., Hayes, S., Galvin, M., Walshe, C., \& Cunningham, C. (2008). The effects of staff training on staff confidence and challenging behavior in services for people with autism spectrum disorders. Research in Autism Spectrum Disorders, 2(2), 311-319.

McDonnell, A. (1997). Training care staff to manage challenging behaviour: An evaluation of a three-day course. British Journal of Developmental Disabilities, 43, 156-161.

Reid, D. H., Rotholz, D. H., Parsons, M. B., Braswell, B. A., Green, C.W., \& Schell, R. M. (2003). Training human service supervisors in aspects of PBS. Journal of Positive Behavior Intervention, 5, 35-46.

Rice, M. E., Helzel, M. F., Varney, D. W., \& Quinsey, V. L. (1985). Crisis prevention and intervention training for psychiatric hospital staff. American Journal of Community Psychology, 13, 289-304.

Richman, G. S., Riordan, M. R., Reiss, M. L., Pyles, D. A. M., \& Bailey, J. S. (1988). The effects of self-monitoring and supervisor feedback on staff performance in a residential setting. Journal of Applied Behavior Analysis, 21, 401-409. 